\title{
SAMPEK SEBAGAI PENGIRING TARI PAMPAGA SUKU DAYAK KENYAH DALAM SAJIAN WISATA DI DESA PAMPANG SAMARINDA KALIMANTAN TIMUR
}

\author{
Muhammad Gilang Ramadhan \\ Program Pascasarjana Universitas Negeri Yogyakarta \\ Email: m.gilangsecret@gmail.com
}

\begin{abstract}
Abstrak
Musik Sampek di Desa Pampang, Samarinda, Kalimatan Timur biasanya dipertunjukkan sebagai pengiring tari-tarian yang bersifat hiburan seperti: Lembada Lasan, Nyelamasakai, Pepatay, Enggang Terbang, Hudoq, Ajai Piling, Anyam Tali, Pampaga dan Leleng. Diantara beberapa pertunjukan musik sampek sebagai pengiring tari-tarian penulis lebih tertarik kepada musik sampek sebagai pengiring Tari Pampaga karena selain terdapat pertunjukan musik sampek sebagai pengiring tari terdapat pula permainan tradisional bilah-bilah bambu yang menghasilkan bunyi-bunyian seperti hentakan irama yang tidak ditemukan pada pertunjukan musik sampek yang lain. Permainan musik sampek sebagai pengiring tari Pampaga saat ini dipertunjukkan secara rutin setiap hari Minggu sebagai sajian wisata. Tulisan ini bertujuan untuk mengetahui struktur musik sampek dan fungsi Musik Sampek sebagai pengiring Tari Pampaga serta musik sampek sebagai pengiring Tari Pampaga dalam sajian wisata. Metode penulisan adalah kualitatif, dengan pendekatan Etnomusikologis. Adapun teori yang digunakan yakni fungsi musik dalam tarian menggunakan teori Oha Graha, struktur musik menggunakan teori Jamalus dan fungsi musik sampek sebagai pengiring tari pampaga sebagai sajian wisata menggunakan teori R.M. Soedarsono.
\end{abstract}

Kata Kunci : Musik Sampek, Tari Pampaga, Desa Pampang.

\begin{abstract}
Sampek music in the village of Pampang, Samarinda, East Kalimantan is usually performed as an accompaniment of dances that are entertainment such as: Lembada Lasan, Nyelamasakai, Pepatay, Flying Hornbill, Hudoq, Ajai Piling, Anyam Tali, Pampaga and Leleng. Among the few Sampek music performances as accompanist dances, the writer is more interested in Sampek music as accompaniment of Pampaga Dance because besides there are Sampek music performances as dance accompaniment there are also traditional games of bamboo blades that produce sounds such as the beat of the beat which are not found in the performances other samp music. The Sampek music game as a accompanist to the Pampaga dance is currently performed routinely every Sunday as a tourist dish. This paper aims to find out the structure of the Sampek music and the function of the Sampek Music as an accompaniment to the Pampaga Dance and the Sampek music as an accompaniment to the Pampaga Dance in a tourist dish. The writing method is qualitative, with an ethnomusicological approach. The theory used is the function of music in dance using Oha Graha theory, the structure of music using the theory of Jamalus and the function of sampek music as accompaniment of pampaga dance as a tourist dish using the theory of R.M. Soedarsono.
\end{abstract}

Keywords: Sampek Music, Pampaga Dance, Pampang Village 


\section{A. Pendahuluan}

Tari Pampaga merupakan tari yang dipertunjukkan untuk menggambarkan aktivitas masyarakat suku Dayak Kenyah di ladang pada zaman dahulu. Namun seiring perkembangan zaman tarian Pampaga saat ini dipertunjukkan secara rutin pada hari minggu sebagai sajian wisata yang dikombinasikan dengan permainan musik Sampek. Perubahan konsep interaksi simbolik yang dilakukan oleh masyarakat merupakan sebuah punya dalam memenuhi kebutuhan, seperti yang diungkapkan oleh Malinowsky (dalam Koentjaraningrat: 1990) bahwa perubahan fungsi kesenian dalam aktifitas masyarakat dipengaruhi oleh kebutuhan. Dampak konsep ini kemudian lahirnya implementasi seni pertunjukan dalam aktifitas baik sebagai hiburan ataupun ritual.

Musik Sampek sebagai pengiring Tari Pampaga di Desa Pampang memiliki keunikan tersendiri dalam pertunjukannya dibandingkan pertunjukan musik sampek sebagai pengiring tari lain yang ada di Desa Pampang. Hal ini dapat dilihat pada pertunjukan Tari Pampaga yang terdapat permainan bilah-bilah bambu yang digunakan oleh sebagian penari ketika permainan musik Sampek selesai dimainkan. Musik sampek dalam iringan tari-tarian Dayak Kenyah mempunyai dua pengertian yaitu sebagai nama instrumen dan praktek musik secara ansambel.

Perubahan nilai yang terjadi pada musik iringan Tari Pampaga dari ritual menuju profan merupakan sebuah fenomana yang unik dimana faktor-faktor yang mempengaruhi transformasi merupakan bagian-bagian yang bersifat kesatuan, seperti salah satunya adalah faktor kebutuhan dan faktor lainnya adalah ekonomi. Transformasi budaya yang terjadi di desa Pampang adalah keseimbangan dari latens-manifest fungsi sebuah kebudayaan dalam aktifitas masyarakat.

\section{Fungsi Primer dan Sekunder}

Soedarsono (2001) menjelaskan bahwa fungsi seni pertunjukan terbagi menjadi dua yaitu fungsi primer dan fungsi sekunder, fungsi primer adalah fungsi ritual dan sekunder adalah hiburan dan solidaritas masyarakat. Konsep relasi primersekunder yang di uraikan oleh Soedarsono mempunyai kesamaan dengan konsep teori fungsional dalam wilayah sosiologi, seperti uraian Merton (dalam Kaplan Manners: 2002) bahwa pertukaran fungsi suatu kebudayaan lumrah terjadi karena kehendak dari masyarakat pemilik kebudayaan. Konsep manifest-latens yang dijelaskan oleh Merton memberikan sebuah dampak, bahwa sebuah 
kesenian dapat berubah fungsinya secara bagian, terintegrasi dengan faktor-faktor pendukungnya, apabila latens adalah sebuah fungsi yang secara umum tidak dikehendaki oleh masyarakat, maka manifest adalah sebuah fungsi yang dikehendaki oleh masyarakat.

\section{B. Metode Penelitian}

Metode penelitian yang digunakan yakni metode kualitatif yakni merupakan metode penelitian yang bersifat deskriptif analitik atau prosedur penelitian yang menghasilkan data deskriptif berupa faktafakta kata-kata tertulis atau lisan dari orangorang dan pelaku yang diamati ( Sugiyono, 2013: 112 ). Metode ini mempunyai teknik pengeumpulan data berupa observasi, wawancara dan dokumentasi.

Penelitian tari pampaga di desa Pampang mempergunakan pendekatan yang digunakan adalah pendekatan etnomusikologis yang mempelajari hubungan antara teks dan konteks (Nakagawa, 2000: 6 ). Hal ini dikarenakan musik dalam iringan tari Pampaga mempunyai hubungan dengan konteks ceremony atau hiburan dalam pertunjukan wisata. Sehingga analisis data dalam penelitian ini melibatkan konsep MeriamRice yaitu musik sebagai dirinya sendiri, musik sebagai sebuah konsep sajian pertunjukan dan intepretasi.

\section{Hasil dan Pembahasan}

1. Tari Pampaga Pada Masyarakat Dayak Kenyah Di Desa Pampang

Tari Pampaga adalah tarian yang melambangkan suatu perangkap yang sengaja dibuat untuk menjepit leher burung pipit yang kerap memakan bulir-bulir padi di ladang. Pada zaman dahulu sebelum suku Dayak Kenyah memanen padi di ladang, mereka melakukan kegiatan yang dinamakan Pampaga yang artinya sebelum membersihkan rumput sudah melaksanakan kegiatan ritual. Melaksanakan ritual tersebut agar mereka terhindar dari hama dan binatang yang kerap memakan bulir-bulir padi di ladang (Wulandari, 2017/2018: 70) .

Ritual tersebut menyembah kepada dewa-dewa agar semua binatang terjepit. Seiring berjalanya waktu masyarakat Dayak Kenyah Desa Pampang sudah mempercayai agama dan meninggalkan ritual tersebut.. Kemudian dari peristiwa tersebut munculah ide dari salah satu tokoh dewan kesenian untuk mengenang peristiwa masa lalu melalui kesenian yaitu bapak Simson Imang. Simson Imang terinspirasi membuat sebuah tarian dari perangkap untuk menjepit burung pipit. 
Tarian tersebut dinamakan Tari Pampaga yang diselenggarakan secara rutin setiap hari minggu siang di rumah Lamin Adat Pemung Tawai (wawancara dengan Simson Imang , 2019).

Tarian Pampaga pada saat ini Ditarikan oleh 16 gadis muda, tarian ini dimainkan dengan menggunakan peralatan bambu dengan diiringi instrumen Sampek sebagai iringan. Permainan Sampek sebagai pengiring tarian Pampaga hanya sebagai pembuka dalam pertunjukan tersebut setelah itu tarian ini diiringi dengan bilahbilah bambu ditarikan dengan melompat di bagian atas bambu semakin lama bambu yang dimainkan semakin cepat sehingga menghasilkan sebuah irama.

2. Musik Sampek dalam Iringan Tari Pampaga di Desa Pampang Samarinda Kalimantan Timur

Sampek adalah alat musik petik tradisional suku dayak kenyah yang berasal dari kepulauan Kalimantan. Instrumen Sampek ini sekilas mirip dengan perahu/ alat transportasi utama masyarakat Kalimantan. Sampek tergolong jenis chordophone yaitu golongan alat musik yang sumber bunyinya berasal dari sejenis tali, kawat, dawai atau senar. Sampek sendiri biasanya digunakan dalam berbagai aktivitas masyarakat Dayak Kenyah di Desa
Pampang. Bagi suku Dayak Kenyah, Sampek sangatlah penting terutama dalam kehidupan mereka menyangkut upacara adat dalam kepercayaan Bugan Malan Paselong Luan. Sampek merupakan sarana untuk menyampaikan permohonan kepada dewa-dewi tertinggi penguasa alam, menyampaikan rasa senang dan kegembiraan atas keberhasian dalam panen, menyampaikan ungkapan kegembiraan atas kedatangan tamu, menyampaikan ungkapan rasa sedih dan susah atas kematian dan bencana, dan juga untuk mengekspresikan rasa keindahan yang tertuang dalam permainan musik sampek ( Irawati, 2018 : 43).

Alat Musik Sampek pada zaman dahulu apabila dimainkan pada siang hari dan malam hari memiliki perbedaan.Apabila dimainkan pada siang hari, umumnya irama yang dihasilkan Sampek menyatakan perasaan gembira dan suka- ria.Hingga kini, kepercayaan akan tuah sampe masih diyakini oleh para sesepuh Dayak, misalnya ketika Sampek dimainkan dalam suatu upacara adat. Saat bunyi petikan Sampek terdengar, seluruh orang akan terdiam, kemudian terdengar sayup-sayup lantunan doa atau mantra yang dibacakan bersama-sama. Dalam suasana seperti ini, tidak jarang di antara mereka ada yang kerasukan roh halus atau roh leluhur. 
Sampek juga dimainkan pada saat acara pesta rakyat atau acara gawai padai, Sampek dimainkan untuk mengiringi tari-tarian yang lemah gemulai ( Muhammad Zabir maimunah, 2018).

Musik Sampek sebagai pengiring tari pampaga suku dayak kenyah pada zaman dahulu Menurut Laing Along digunakan sebagai pengantar doa-doa kepada dewadewa dan ungkapan syukur atas keberhasilan panen dan tari Pampaga adalah tari-tarian yang menceritakan kehidupan masyarakat dayak kenyah di ladang, mulai bertanam padi hingga mengusir hama. Tarian ini biasa dilakukan sebelum memetik hasil panen yang melambangkan suatu perangkap yang sengaja dibikin untuk menjepit leher burung pipit yang kerap memakan bulirbulir padi di ladang. Tarian ini ditunjukan sebagai permohonan kepada dewa-dewa agar bulir- bulir padi di ladang tidak dimakan oleh hama.

Berbeda dengan saat ini karena kepercayaan yang berakar pada animisme, dinamisme dan totenisme mulai berkurang di desa Pampang. Pada Akhirnya, terjadi perubahan tatanan kehidupan masyarakat suku dayak kenyah di desa Pampang hingga mempengaruhi aktivitas masyarakatnya. Di dalam kehidupan masyarakat dayak kenyah di desa Pampang saat ini rata-rata mayoritas penduduknya menganut agama kristen sehingga berbagai pertunjukan yang ada di desa Pampang hanya bersifat hiburan termasuk pertunjukan musik Sampek sebagai pengiring tari Pampaga (Wawancara dengan Laing Along, 2019).

3. Struktur Musik Sampek Sebagai Pengiring Tari Pampaga

Struktur/ Bentuk musik adalah susunan dan hubungan antara unsur-unsur musik dalam suatu lagu sehingga menghasilkan suatu lagu yang bermakna. Bentuk ataupun struktur lagu itu merupakan susunan dan hubungan antara unsur musik dalam suatu lagu, sehingga menghasilkan suatu komposisi atau lagu yang bermakna atau mempunyai suatu arti ( struktur musik, 2010)

Komposisi Musik adalah mencipta suatu lagu. Dasar pembentukan lagu mencakup pengulangan satu bagian lagu yang disebut repitisi, pengulangan dengan berbagai perubahan atau yang disebut dengan variasi ataupun sekuen, serta penambahan bagian yang baru yang berlainan atau berlawanan ( kontras), dengan selalu memperhatikan keseimbangan antara pengulangan dan perubahannya (Jamalus, 1998 : 36).

Dalam permainan musik sampek 
sebagai pengiring Tari Pampaga, musik yang digunakan terdapat 3 instrumen. Sampek pertama memainkan melodi, sampek kedua sebagai pemberi hiasan, sampek ketiga sebagai pengiring. Selain itu di dalam tari Pampaga terdapat permainan bilah-bilah bambu. Berikut ini struktur musik sampek sebagai pengiring Tari Pampaga:

\section{Introduction}

Introduction adalah pengantar atau bagian permulaan lagu atau pembukaan, adapun introduction musik sampek sebagai pengiring Tari Pampaga di Desa Pampang Kecamatan Samarinda Utara yaitu sebagai berikut.

\section{Sukat $4 / 4$}

$$
\begin{aligned}
& \text { Sampek 1: } \overline{\dot{5} \dot{6}}, \overline{i \dot{i}} \overline{i \dot{i}} \overline{\dot{i} \dot{i}} \dot{3 \dot{3} \dot{2}}, \overline{i \dot{i}} \overline{i \dot{6}} 5 \overline{5 \dot{\sigma}} \\
& \text { Sampek 2: } \overline{56}, \overline{11} \overline{11} \overline{21} 3 \overline{\overline{32}}, \overline{11} \overline{16} 5 \overline{56} \\
& \text { Sampek 3: } \overline{56}, \overline{11} \overline{11} \overline{21} 3 \overline{\overline{32}}, \overline{11} \overline{16} 5 \overline{56}
\end{aligned}
$$

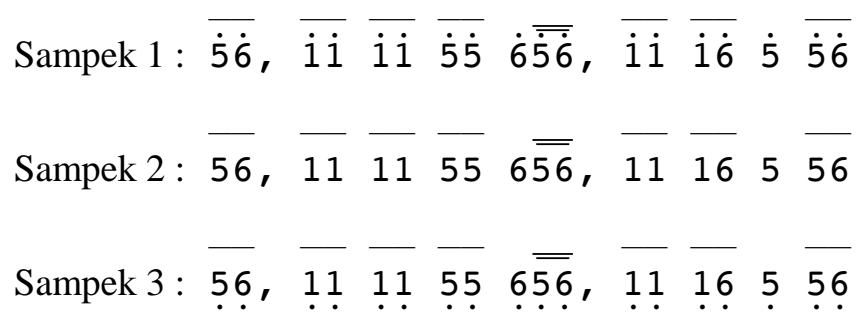

Ketika musik introduction pemain musik sampek bermain secara bersama- sama lalu para penari pampaga juga mengadakan gerakan awal atau gerakan pembuka dengan melakukan gerakan seperti burung enggang terbang. Gerakan burung itu sendiri merupakan ayunan naik turun kedua tangan dari bahu hingga sejajar pinggang penari, seperti gerakan burung yang sedang terbang. 


\section{Melodi pokok}

Melodi Pokok yaitu lagu asli dari instrumen musik Sampek sebagai pengiring tari pampaga tersebut.

\section{Sukat $4 / 4$}

Sampek 1: $\overline{\dot{5} \dot{\sigma}}, \overline{i \dot{1}} \overline{i \dot{i}} \overline{\dot{2} \dot{3}} \dot{\overline{3} \dot{2}}, \overline{i \dot{i}} \overline{i \dot{6}} 5 \overline{5 \dot{\sigma}}$

Sampek 2: $\overline{56}, \overline{11} \overline{11} \overline{21} 3 \overline{\overline{32}}, \overline{11} \overline{16} 5 \overline{56}$

Sampek 3: $\overline{56}, \overline{11} \overline{11} \overline{21} 3 \overline{3 \underline{32}}, \overline{11} \overline{16} 5 \overline{5} \overline{56}$

Sampek 1: $\overline{\dot{5} \dot{\sigma}}, \overline{i \dot{i}} \overline{i \dot{i}} \overline{\dot{5} \dot{5}} \dot{\bar{\sigma}} \overline{\dot{5} \sigma}, \overline{i \dot{i}} \overline{i \dot{\zeta}} \dot{5} \overline{\dot{5} \dot{6}}$

Sampek 2: $\overline{56}, \overline{11} \overline{11} \overline{55} 6 \overline{\overline{56}}, \overline{11} \overline{16} 5 \overline{56}$

Sampek 3: $\overline{56}, \overline{11} \overline{11} \overline{55} 6 \overline{\overline{56}}, \overline{11} \overline{16} 5 \overline{56}$

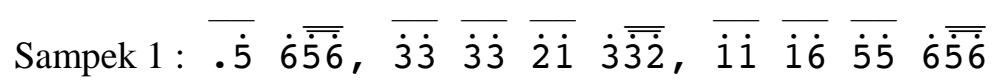

Sampek 2: $\overline{.5} 6 \overline{\overline{56}}, \overline{33} \overline{33} \overline{21} 3 \overline{\overline{32}}, \overline{11} \overline{16} \overline{55} 6 \overline{\overline{56}}$

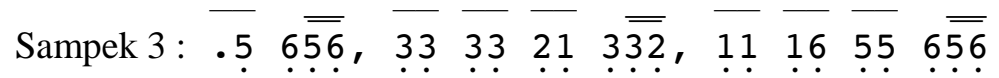

Pada bagian musik ini para penari pampaga melakukan gerakan hentak tangan yang diartikan sebagai hiburan dan bersatu, pada gerak bagian ini para penari memecah, membentuk barisan menjadi dua bagian dengan arah hadap menghadap ke arah penonton.

\section{Coda}

Coda ialah bagian yang ditambahkan pada akhir lagu bertujuan untuk menghasilkan titik klimaks atau sebagai gongnya adapun coda musik sampek adalah sebagai berikut. 


\section{Sukat $4 / 4$}

Sampek 1: $\overline{\dot{5} \dot{\sigma}}, \overline{i \dot{i}} \overline{i \dot{i}} \overline{\dot{2} \dot{i}} \overline{3} \overline{\overline{3 \dot{2}}}, \overline{i \dot{i}} \overline{i \dot{\sigma}} 5 \overline{\dot{5} \dot{6}}$

Sampek 2: $\overline{56}, \overline{11} \overline{11} \overline{21} 3 \overline{\overline{32}}, \overline{11} \overline{16} 5 \overline{56}$

Sampek 3: $\overline{56}, \overline{11} \overline{11} \overline{21} 3 \overline{\overline{32}}, \overline{11} \overline{16}$ $5 \overline{56}$

Sampek 1: $\overline{\dot{5} \dot{\sigma}}, \overline{i \dot{i}} \overline{i \dot{i}} \overline{\dot{5} \dot{5}} \dot{\overline{6} \dot{5}}, \overline{i \dot{i}} \overline{i \dot{\sigma}} \dot{5} \overline{\dot{5} \dot{\sigma}}$

Sampek 2: $\overline{56}, \overline{11} \overline{11} \overline{55} \overline{656}, \overline{11} \overline{16} 5 \overline{56}$

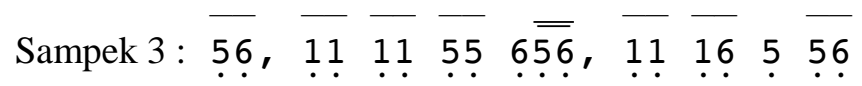

Sampek 1: $\overline{. \dot{5}} \dot{6} \overline{\dot{5} \dot{6}}, \overline{\dot{3} \dot{3}} \overline{\dot{3} \dot{3}} \overline{\dot{2} \dot{1}} \dot{3} \overline{\dot{3} \dot{2}}, \overline{i \dot{1}} \overline{i \dot{\sigma}} \overline{\dot{5} \dot{5}} \dot{6} \overline{\dot{5} \dot{6}}$

Sampek 2: $\overline{.5} 6 \overline{\overline{56}}, \overline{33} \overline{33} \overline{21} 3 \overline{\overline{32}}, \overline{11} \overline{16} \overline{55} 6 \overline{\overline{56}}$

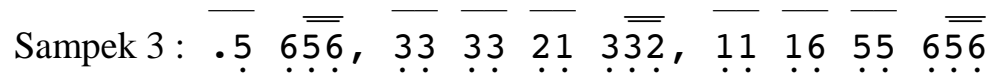

Pada bagian musik ini para penari melakukan perpindahan gerakan dengan membentuk lingkaran yang melambangkan bersatu dalam satu lingkaran. Kemudian para penari membentuk gerakan memecah yang diartikan sebagai pergerakan dalam menghancurkan bintang yang mengganggu. Pada bagian memecah ini para penari juga mempersiapkan properti berupa bilah-bilah bambu yang akan digunakan untuk menari bersama panra penonton yang ingin mencoba Tari Pampaga. Setelah permainan musik sampek selesai ditandai dari bunyi bilah-bilah bambu barulah permainan bilah-bilah bambu mulai masuk untuk mengiringi tarian ini. Berikut ini pola-pola permainan bilah-bilah bambu dalam tarian Pampaga

P.Bambu: $d d t d d t, d d t d d t$ 


\section{Selonding \\ Jurnal Etnomusikologi}

$$
\text { Keterangan : } \begin{aligned}
\mathrm{d} & =\text { dug } \\
\mathrm{t} & =\mathrm{trak}
\end{aligned}
$$

Penulisan ritmis pada permainan properti bilah-bilah bambu yang digunakan oleh penari pada saat pementasan, digunakan istilah dug dan trak. Warna Suara ( tune colour) dilambangkan dengan huruf $\mathrm{d}$ $=$ dug dan $\mathrm{t}=$ trak. Pola- pola permainan bilah-bilah bambu itu diulang-diulang semakin lama semakin cepat sehingga apabila terjepit berarti sudah terperangkap dalam suatu jebakan hal itulah yang menggambarkan bahwa inilah kehidupan masa lampau masyarakat Dayak Kenyah pada zaman dahulu. Kemudian apabila kaki kita terjepit maka penonton tepuk tangan

4. Fungsi Musik Sampek dalam Iringan Tari Pampaga

Musik sebagai pengiring Tari Pampaga memiliki fungsi yang penting dalam tarian karena antara musik dan tari saling terkait satu sama lain dan musik berperan penting dalam menghidupkan suasana tarian. Menurut Oha Graha, fungsi musik dalam tari adalah memberi irama, memberi ilustrasi, membantu mempertegas ekspresi gerak dan rangsangan bagi penari (Graha, 1997:44). Dari Teori di atas penulis akan menjabarkan fungsi musik dalam tarian dengan disesuaikan dengan obyek penelitian yakni fungsi musik sampek sebagai iringan Tari Pampaga pada masyarakat suku Dayak Kenyah di Desa Pampang yakni sebagai berikut.

a. Memberi irama (membantu mengatur waktu)

Musik Sampek dalam tarian pampaga berperan penting dalam mengatur waktu cepat dan lambatnya suatu gerakan karena tanpa adanya iringan sampek tari tidak akan berjalan. Contoh: ketika musik sampek sebagai pengiring Tari Pampaga dimainkan di awal sebagai pembuka, Tarian Pampaga mulai masuk. Hal ini sebagai tanda bahwa musik memberikan isyarat kepada penari untuk memulai tarian dan ketika musik berhenti tarian juga berakhir dan ganti kesesi selanjutnya.

b. Memberi ilustrasi atau gambaran suasana Dalam tari, suasana atau ilustrasi sangat erat hubungannya dengan watak penari, terutama pada tari tradisional yang sangat memerlukan berbagai suasana. 
Adapun watak dalam suasana tari antara lain watak luguh/ halus, watak lenyap/ ganjen, dan gagah (Soedarsono, 1997:40). Dalam hal ini musik sampek memberikan suasana dalam tarian Pampaga karena dalam setiap gerakan Tari Pampaga terdapat gambaran kisah hidup masyarakat Dayak Kenyah. Contoh : ketika musik sampek dimainkan dalam iringan Tari Pampaga pada bagian awal penari menarikan gerakan burung enggang terbang. Gerakan burung itu sendiri merupakan ayunan naik turun kedua tangan dari bahu hingga sejajar pinggang penari, seperti gerakan burung yang sedang terbang.

c. Membantu mempertegas ekspresi gerak Dalam tarian sudah barang tentu mempunyai tekanan-tekanan gerak yang diatur oleh tenaga. Mempertegas ekspresi gerak akan lebih sempurna diiringi atau dipertegas oleh hentakan instrumen musik sebagai pengiring tari. Dalam hal ini jika kita kaitkan antara musik sampek dan tari pampaga memiliki hubungan dalam mempertegas gerakan sang penari. Yang dimana ketika musik sampek bermain pada sekuen naik tarian pun juga berubah mengikuti hentakan instrumen tersebut. Contoh : Ketika musik sampek sebagai iringan Tari Pampaga dimainkan pada bagian kedua terdapat gerak hentak/ tepuk tangan yang diartikan sebagai hiburan dan bersatu dan gerak pada bagian ini para penari memecah, membentuk barisan dengan arah menghadap ke arah penonton.

\section{d. Rangsangan bagi penari}

Soedarsono mengatakan elemen dasar dari tari adalah gerak dan ritme, Maka elemen dasar dari musik adalah nada ritme dan melodi. Sejak zaman prasejarah sampai sekarang dapat dikatakan dimana ada tari disitu pasti ada musik, musik dalam tari bukan hanya sekedar pengiring, tetapi musik adalah rekan tari yang tidak boleh ditinggalkan, musik dapat memberikan suatu irama yang selaras sehingga dapat membantu mengatur ritme atau hitungan dan dapat juga memberikan gambaran dalam ekspresi suatu gerak ( Soedarsono, 1997:46). Contoh : Ketika musik sampek dimainkan para penari mengikuti alunan musik sampek yang dimainkan semakin keras dan lembut musik yang dimainkan para penari mengikuti sambil menikmati iringan musik. Jika iringan musik sampek berhenti maka tarian juga ikut berhenti.

5. Fungsi Musik Sampek sebagai pengiring Tari Pampaga sebagai sajian Wisata Di Desa Pampang Samarinda Kalimantan Timur. 
Pertunjukan Musik Sampek di Desa Pampang merupakan kemasan seni wisata, maquet mengungkapkan bahwa produk seni berdasarkan jenis penikmatnya dibagi menjadi dua kategori yaitu :

a. Seni yang memang dibuat untuk dinikmati masyarakatnya (art by destination).

b. Seni yang dibuat memang untuk orang lain (pendatang/wisatawan) disebut dengan art by metamorphosis (Soedarsono, 1999 : 3).

Dalam hal ini seni wisata masuk dalam kategori kedua. Dengan demekian seni wisata harus mampu menyesuaikan dengan selera penikmatnya. Kemasan seni wisata memiliki ciri-ciri yaitu 1.) Tiruan dari Aslinya 2.) Bentuk pementasannya singkat 3.) Penuh Variasi 4.) Tidak Sakral dan murah harganya ( Soedarsono, 1999 : 8). Dari beberapa ciri-ciri seni wisata disebutkan diatas. Seni Wisata di Desa Pampang terlihat memakai beberapa konsep tersebut. Adapun penjelasannya adalah sebagai berikut.

1) Tiruan dari Bentuk Aslinya

Pertunjukan seni tradisional Sampek sebagai pengiring Tari Pampaga sebagai kemasan seni wisata masih menyerupai bentuk aslinya, walaupun terdapat perbedaan dari segi keaslinya. Dalam

Pertunjukan kesenian musik sampek produk lamanya Sampek sebagai pengiring Pampaga dimainkan pada saat upacara pengusiran hama binatang yang digelar di Tengah lapangan atau sawah yang akan ditanami. Berbeda dengan saat ini musik sampek sebagai pengiring tari pampaga hanya bersifat hiburan dan hanya disuguhkan untuk para penonton saja.

2) Bentuk Pementasannya Singkat.

Musik Sampek sebagai pengiring Tari Pampaga produk lama biasanya dimainkan dengan waktu cukup lama dalam setiap pementasannya, sedangkan saat ini hanya dimainkan dengan waktu yang cukup singkat yaitu sekitar 10 menit.

3) Variatif

Pertunjukan seni wisata musik sampek terbilang cukup variatif hal itu terlihat terdapat perpaduan antara ketiga permainan musik sampek saling mengisi satu sama lain dan permainan bilah-bilah bambu dengan memerhatikan esensi nilai dikandungnya..

4) Tidak Sakral

Kesenian musik sampek sebagai pengiring tari pampaga saat ini tidak sakral karena dimainkan untuk menghibur penonton dan tidak ada pengunaan unsur ritual didalamnya.

5) Murah Harganya

tergolong terjangkau harganya untuk menyaksikan pertunjukan para pengunjung 
dikenakan tarif Rp. 20.000 sedangkan untuk berfoto bersama masyarakat Dayak Kenyah di Desa Pampang para pengunjung

\section{Simpulan}

Struktur Musik adalah susunan dan hubungan antara unsur-unsur musik dalam suatu lagu sehingga menghasilkan suatu lagu yang bermakna, sedangkan unsurunsur musik itu meliputi : melodi, harmoni, ritme, dinamik. Struktur musik sampek sebagai pengiring Tari Pampaga dalam sajian wisata di Desa Pampang Samarinda Kalimantan Timur dimainkan secara berulang- ulang dengan menggunakan introduction, melodi pokok dan coda. Sampek 1 bermain melodi oktaf tinggi, sampek 2 bermain melodi oktaf sedang, sampek 3 bermain oktaf rendah. Fungsi Musik Sampek dalam mengiringi Tari Pampaga di Desa Pampang Samarinda Kalimantan Timur dalam kemasan wisata adalah berfungsi memberi irama, memberi ilustrasi, mempertegas ekspresi gerak dan rangsan bagi penari.Fungsi pertunjukan musik sampek sebagai pengiring Tari Pampaga dalam sajian wisata di Desa Pampang adalah tiruan dari aslinya, bentuk pementasanya singkat, variatif, ditanggalkan nilai sakralnya, murah harganya. dikenakan biaya Rp. 25.000 , - untuk empat kali sesi foto

\section{E. Daftar Pustaka}

Graha, Oha. 1997. Fungsi Musik Dalam Tari. Jakarta : Sinar Harapan Morris, Desmond. Man Watching. New York: Harry N.A Brams, INC., Publisher.

Hadibrata, Wahyu. 2016. “ Musik Sampek Sebagai Kemasan Wisata Di Desa Budaya Pampang Kalimantan Timur ”. Skripsi untuk menempuh derajat Strata 1 Program Studi Etnomusikologi Fakultas Seni Pertunjukan Institut Seni Indonesia Yogyakarta.

Irawati, Eli. 2018. Belajar Musik Sampek. Yogyakarta: Institut Seni Indonesia.

Jamalus, 1998. Pendidikan Kesenian 1 Musik. Dirjen Dikti: Jakarta.

Kaplan, Manners dan Manners, Albert, 2002. Teori Budaya terj. Landung simatupang. Yogyakarta. Pustaka Pelajar.

Nakagawa, Shin. 2000. Musik dan Kosmos: Sebuah Pengantar Etnomusikologi Jakarta: Yayasan obor indonesia.

Ramadhan, Muhammad Gilang. 2020. Strata 1: "Sampek Sebagai Pengiring Tari Pampaga Dalam Sajian Wisata Di 
Desa Pampang Samarinda Kalimantan Timur" Skripsi untuk mencapai derajat S-1 pada program studi Etnomusikologi, Fakultas Seni Pertunjukan, Institut Seni Indonesia. Yogyakarta.

Soedarsono, R.M. 1997. Tari-tarian Indonesia 1. Jakarta : Depdikbud.

Soedarsono, R.M. 1999. Seni Pertunjukan Indonesia \& Pariwisata, Bandung: Masyarakat Seni Pertunjukan Indonesia.

Soedarsono, R.M. 2001. Metodologi Penelitian Seni Pertunjukan dan Seni Rupa. Bandung: Masyarakat
Seni Pertunjukan Indonesia.

Sugiyono. 2013 . Metode Penelitian Kualitatif; Pendekatan Kualitatif dan R \& D Bandung: Alfabeta.

Wulandari, PS. 2017. "Fungsi Tari Pampaga Di Desa Budaya Pampang Kalimantan Timur ". Skripsi untuk menempuh derajat Strata 1 Program Studi Tari Jurusan Tari Fakultas Seni Pertunjukan Institut Seni Indonesia Yogyakarta.

Zabir, Muhammad Maimunah. 2018. Sampek dalam kehidupan Suku Dayak Kenyah. http.//definisi-musik-sampek.com/2018.html. Diakses pada 3 november 2019. 
Muhammad Gilang (Sampek Sebagai....)

pp. 15-28

Selonding

Jurnal Etnomusikologi 